\title{
NEPHRO-PROTECTIVE ACTIVITY OF ISOLATED METHANOL FRACTIONS PHYTO-COMPOUND FROM BARK OF TERMINALIA ARJUNA
}

\author{
SHREYA MANDAL ${ }^{1}$, ARPITA PATRA ${ }^{1}$, SHRABANI PRADHAN ${ }^{1}$, SUCHISMITA ROY ${ }^{1}$, ANIMESH SAMANTA ${ }^{1}$, KOUSHIK $^{2}$ \\ DAS ${ }^{1}$, ATISKUMAR CHATTOPADHYAY ${ }^{2}$, DILIP KUMAR NANDI ${ }^{*}$
}

1Department of Nutrition, Microbiology and Human Physiology, Raja N. L. Khan Women's College, Paschim Medinipur, 721102, West Bengal, India, ${ }^{2}$ Secretary, Faculty Council of Science, Jadavpur University, Kolkata 700032, West Bengal, India Email: dilipnandi2004@yahoo.co.in

Received: 12 Jul 2017 Revised and Accepted: 02 Nov 2017

\begin{abstract}
Objective: The aim of this study was to evaluate the antioxidant property of the isolated phytocompounds from TA (Terminalia arjuna) bark and in vivo study for nephro-protective and oxidative stress reducing activity in experimentally induced albino male rats.

Methods: Fractions from methanol crude TA extract were collected by column chromatography and F27, F28, F29 fractions were selected on the basis of antioxidant property by 2,2-diphenyl-1-picrylhydrazyl (DPPH) scavenging assay. The in vivo study performed by 30 albino male rats which were randomly divided into five groups: Group I (control)were taken normal food and water, Groups II (uremic) were injected acetaminophen intraperitoneally at the dose of $500 \mathrm{mg} / \mathrm{kg} / \mathrm{d}$ for $10 \mathrm{~d}$, Group III, IV and V(extract treatment) acetaminophen intraperitoneally at the dose of 500 $\mathrm{mg} / \mathrm{kg} / \mathrm{d}$ for $10 \mathrm{~d}$ with co-administered orally of methanol fraction F27, F28, F29 at the dose of $100 \mathrm{mg} / \mathrm{kg} / \mathrm{d}$ for $15 \mathrm{~d}$ respectively.
\end{abstract}

Results: After scarification of rats, the uremic marker plasma urea (80\%), creatinine (85\%) were elevated and antioxidant enzyme marker such as plasma SOD and catalase level were significantly increased $(\mathrm{p}<0.05)$ in Group IV compared to Group II. The total phenolic content of the F28 methanolic fraction was $(815.48 \pm 8.11) \mathrm{mg}$ gallic acid equivalent/g of extract. For isolation of available compound by ${ }^{1} \mathrm{H}$ NMR study in F28 methanol fraction of TA bark was arjunoside IV which contained olefinic proton (a pair of carbon atom linked with double bond).

Conclusion: Among the three methanolic fraction of TA bark, F28 was shown best antioxidative, nephron-protective and oxidative stress reducing property.

Keywords: Terminalia arjuna, Column chromatography, DPPH, ${ }^{1} \mathrm{H}$ NMR, Kidney disease

(C) 2017 The Authors. Published by Innovare Academic Sciences Pvt Ltd. This is an open access article under the CC BY license (http://creativecommons.org/licenses/by/4.0/) DOI: http://dx.doi.org/10.22159/ijpps.2017v9i12.21274

\section{INTRODUCTION}

Medicinal or herbal plants are the willpower of popular scheme of medicines and which are highly valuable and incredible source for the treatment of numerous deteriorating diseases in the form of medicines [1]. In the present scenario kidney related different diseases like acute renal failure, chronic renal failure, nephrotic syndrome, end stage renal disease (ESRD), acute streptococcal glomerulo-nephritis, glomerular nephritis, non-streptococcal glomerulo-nephritis are the direct causes like lymphatic nephropathy, diabetes nephropathy and as well as infectious nephrotoxicity are the vital complication across the world [2]. Kidney disease is one of the most common health problems and which occurs when body is disclosed to the drugs or toxins. There are some potential therapeutic agents like aminoglycoside, antibiotics, NSAID's, chemotherapeutic agents can unfavorably affect the kidney, resulting in acute renal failure, chronic renal failure and nephrotic syndrome to the therapeutic weaponry in present years. Paracetamol is known as acetaminophen which is commonly used as an analgesic and antipyretic drug which used in the high doses can causes nephrotic tubular damage, uremia and oxidative stress. Overdose of acetaminophen (APAP) can causes nephro-toxicity. It produced reactive intermediate product $\mathrm{N}$-acetyl-p-benzoquinoneimine (NAPQI) by using cytochrome P450 due to exhaustion of glutathione sulfhydryl (GSH). It also initiated the lipid peroxidation and leading to renal failure [3]. Some secondary metabolites are reported to be present in medicinal plant [4] of plant, provide definite physiological action on the human body [5] and these secondary metabolites have different bioactive properties like anticancer, antidiabetic, antihelminthic, antimutagenic, antibacterial, antidermatic etc. These secondary metabolites [4] of plants include tannins, alkaloids, carbohydrates, triterpenoids, steroids, flavonoids and phenolic compounds. These phyto- constituents are used as a natural or herbal medicine and their extracted products are used for long time to treat various chronic diseases in the world. Because plant products are frequently considered to be less toxic and free from side effects than synthetic ones. The medicinal plants like Terminellia arjuna (TA) has been a part of ayurvedic medicinal system. The bark of TA contains different types of phytoconstituents like phenols, triterpenoids, flavonoids, tannins and others phytocompound and they also have antioxidant and antimicrobial activity [6].

Therefore, the present study was aimed to evaluate the nephroprotective activity of phytocompounds which were isolated from the methanol fractions of the bark of Terminalia arjuna which belong to family Combretaceae by using in rat model.

\section{MATERIALS AND METHODS}

Drugs and chemicals

Acetaminophen (paracetamol, $N$-acetylp-aminophenol; APAP) was purchased from AshChemie India. It administered intraperitoneally with saline water. All the chemicals were used for Biochemical tests including Urea, Creatinine kit, Methanol (analytical grade), $\mathrm{H}_{2} \mathrm{O}_{2}$, Pyragallol, Silica Gel and Ascorbic acid were purchased from Merck Specialities Private Limited (Mumbai, India) and HiMedia Laboratories Pvt. Ltd. (Mumbai, India). DPPH and other chemicals were purchased from Sigma Aldrich, India.

\section{Ethical statement for animal experimentation}

Animal experiments were permitted by Ministry of Environment, Government of India under registration no. 1905/PO/Re/S/ 2016/CPCSEA issued by Committee for the Purpose of Control and Supervision of Experiments on Animals (CPCSEA) and approved by the Institutional Animal Ethic Committee (IAEC) of Department of 
Nutrition, Raja N. L. Khan Women's College, Paschim Medinipur, and West Bengal, India.

\section{Collection, identification and preparation of plant materials}

The bark of TA was collected from University road, Vidyasagar University, Midnapore, Paschim Medinipur, district of West Bengal. Plant material was identified by the taxonomist of the Botany Department at the Raja N. L. Khan Women's College, Midnapore. The collected TA barks were cut into small pieces. Plant parts were dried in an incubator for seven days at $40^{\circ} \mathrm{C}$, crushed in an electrical grinder and then the powder was separated by sieve, weight and stored in air tight container.

\section{Preparation of methanol extract}

Twenty-five grams of bark powder of said plant material was washed in $100 \mathrm{ml}$ of petroleum ether for $24 \mathrm{~h}$ for removed the greasy, pigmented, non-polar materials. Then discard the petroleum ether and dried it in incubator. Then the dried material was dissolved in $250 \mathrm{ml}$ methanol for $24 \mathrm{~h}$. The extract was filtered through Whatman No.1 filter paper and the resulting filtrate was dried in the air, weight and stored in air tight container.

\section{Preparation of methanol fraction by column chromatography}

The column $(2 \mathrm{~cm} \times 25 \mathrm{~cm})$ was packed with a solution of silica gel with distilled water using the wet slurry method. This involves preparing a solution of silica gel, with distilled water in this case, in a beaker and subsequently adding this unto the column till it is about three-fourths filled. The solution was stirred for dispersal and quickly added to the column before the gel settles. This method was used to prevent the trapping of air bubbles. A ball of wool was pushed into the column to settle atop the packed silica gel. A substantial amount of diethyl ether: acetone: methanol (5:3:2) was poured continuously into the column and allowed to drain but prevented from reaching the cotton wool. Then $10 \mathrm{ml}$ of the methanol extract of TA bark was introduced into the column. The quantity collected was poured back into the column. Periodically, a piece of rubber tubing was used to agitate the column to allow for the escape of trapped air bubbles. About 35 fractions are eluted and collected in dry glass bottles. The column fractions were determined by $\%$ of radical scavenging activity using DPPH by modified colorimetric method [7].

\section{Antioxidant activity determination by DPPH free radical scavenging assay}

DPPH radical scavenging activity of methanol fractions of TA bark were measured by modified method of Barros et al., 2008 [8]. Ascorbic acid (Standard) was dissolved in methanol and methanol fractions were used as the test solutions. About $1 \mathrm{ml}$ of each fraction was placed into test tubes and $0.5 \mathrm{ml}$ of $1 \mathrm{mmol} / \mathrm{l} \mathrm{DPPH}$ solution in methanol was added. The test tubes were incubated for $15 \mathrm{~min}$ and the absorbance was read at $517 \mathrm{~nm}$. A blank solution was consisted of DPPH dissolved in same amount of methanol. The DPPH radical scavenging activity percentage was calculated by using the following formula:

DPPH radical scavenging activity $(\%)=[$ A517 control A517extract)/ A517control] x 100

\section{Selection of animals and care}

The study was conducted on 30 healthy, adult, male albino rats of Wister strain (supplied from Ghosh animals, Animal foods and animal cages supplier, Kolkata, India 700054) having a body weight of $90 \pm 20 \mathrm{~g}$. They were acclimatized to laboratory conditions for two weeks prior to experimentation. The animals were grouped and housed in polyacrylic cages $(38 \times 23 \times 10 \mathrm{~cm})$ three rats/cage in a temperature-controlled room $\left(22 \pm 2{ }^{\circ} \mathrm{C}\right)$ with $12-12 \mathrm{~h}$ dark-light cycles (8.00-20.00 h light, 20.00-8.00 h dark) at a humidity of 50 \pm 10 $\%$. They were provided with standard food and water ad libitum. Animal care was provided according to the guiding principle for the care and use of animals [9]. This experimental design was approved by Institutional Animal Ethical Committee.

\section{Grouping of animal}

Thirty healthy adult male Wister strain rats were divided into five groups with each group contains 6 rats on the basis of matching the body weights.
Group-I or Control-Six animals were subjected to control group. They were sheltered at room temperature $\left(25 \pm 3^{\circ} \mathrm{C}\right)$ and feed normal diet and water ad libitum.

Group-II or acetaminophen induced uremia-Six animals were randomly placed in cage with normal diet and injected with acetaminophen at the concentration of $500 \mathrm{mg}$ with de-ionized water $5 \mathrm{ml} / \mathrm{kg}$ of body weight/d/rat for $10 \mathrm{~d}$ to achieve uremia.

Group-III or acetaminophen with treatment by methanol fraction (F27)-Acetaminophen induced uremia with co-administration orally of $100 \mathrm{mg}$ F27 methanol fraction of TA bark with de-ionized water 5 $\mathrm{ml} / \mathrm{kg}$ of body weight/d/rat for $15 \mathrm{~d}$.

Group-IV or acetaminophen with treatment by methanol fraction (F28)-Acetaminophen induced uremia with co-administration orally of $100 \mathrm{mg} \mathrm{F} 28$ methanol fraction of TA bark with de-ionized water 5 $\mathrm{ml} / \mathrm{kg}$ of body weight $/ \mathrm{d} / \mathrm{rat}$ for $15 \mathrm{~d}$.

Group-V or acetaminophen with treatment by methanol fraction (F29)-Acetaminophen induced uremia with co-administration orally of $100 \mathrm{mg}$ F29 methanol fraction of TA bark with de-ionized water 5 $\mathrm{ml} / \mathrm{kg}$ of body weight/d/rat for $15 \mathrm{~d}$.

\section{Animals sacrificed and blood collection}

This experimental design was continued for $15 \mathrm{~d}$. After $15 \mathrm{~d}$, the animals were sacrificed and blood was collected from the aorta for different biochemical analysis.

\section{Blood uremia profile measurement}

\section{Biochemical estimation of blood urea}

The collected blood was centrifuged and plasma fraction was separated. Urea level of plasma was measured by commercially available standard Blood Urea Kit by Semiautoanalyzer by standard protocol for photometric determination of urea according to the Urease GLDH method (kinetic UV test) [10].

\section{Biochemical estimation of blood creatinine}

The collected blood was centrifuged and plasma fraction was separated. The plasma creatinine level was measured by commercially available standard Blood Urea Kit by using Semiautoanalyzer by standard protocol for phtotometric determination of creatinine based on Jaffe kinetic method without de-proteinization [11].

\section{Antioxidant enzymes measurement \\ Biochemical assay of catalase activity}

Catalase activity (CAT) was measured biochemically. For the evaluation of CAT in plasma, the collected blood was centrifuged and the plasma fraction was separated. Following this, $0.5 \mathrm{ml}$ of hydrogen peroxide $\left(\mathrm{H}_{2} \mathrm{O}_{2}\right)$ and $2.5 \mathrm{ml}$ of distilled water were mixed and reading of absorbance was noted using a spectrophotometric cuvette at $240 \mathrm{~nm} .40 \mu \mathrm{l}$ of plasma were added separately and six subsequent readings were noted at 30 s intervals [12].

\section{Biochemical assay of superoxide dismutase (SOD)}

The whole blood was centrifuged and plasma fraction was separated. The super oxide dismutase (SOD) activity of plasma will be estimated by measuring the percentage of inhibition of the pyragallol auto-oxidation by SOD using spectrophotometer at 420 $\mathrm{nm}$ and values were expressed as mmol of $\mathrm{H}_{2} \mathrm{O}_{2}$ consumption/dl of plasma/min [13].

\section{Determination of total phenol content}

The amount of phenol compounds in the methanol fraction of TA bark was determined using Folin-Ciocalteu reagent, according to the modified method [14]. One $\mathrm{ml}$ of the plant extracts/standard solution was mixed with $5 \mathrm{ml}$ Folin-Ciocalteu reagent and $4 \mathrm{ml}$ ( $7.5 \%$ sodium carbonate) of sodium carbonate $\left(\mathrm{Na}_{2} \mathrm{CO}_{3}\right)$. The tubes were vortexed for few seconds and allowed to stand for $30 \mathrm{~min}$ at $20^{\circ} \mathrm{C}$ for colour development. Absorbance of samples and standard were measured at $765 \mathrm{~nm}$ using spectrophotometer against blank. A 
typical blank solution contained the solvent used to dissolve the plant extract. The total content of phenolic compounds plant extracts in gallic acid equivalents (GAE) was calculated using the following equation:

$$
\mathrm{C}=(\mathrm{c} \times \mathrm{V}) / \mathrm{m}
$$

Where $\mathrm{C}=$ total content of phenolic compounds, $\mathrm{mg} / \mathrm{g}$ plant extract, in GAE, $c=$ the concentration of gallic acid established from the calibration curve $(\mathrm{mg} / \mathrm{ml}), \mathrm{V}=$ the volume of extract in $\mathrm{ml}$, and $\mathrm{m}=$ the weight of plant extract in $\mathrm{g}$.

\section{${ }^{1} \mathrm{H}$ NMR analysis}

${ }^{1} \mathrm{H}$ NMR spectra of methanol fraction (F28) of bark of TA was recorded using a Bruker AMX-400 (400 MHz) instrument and the spectra were referenced to the deuterated solvent ( ${ }_{6}{ }_{6} \mathrm{DMSO}$ ) signals and chemical shifts were recorded as $\delta$ values. The result graph was compared with the reference chart and possible functional group present in the plant were determined [15].

\section{Statistical analysis}

The values were expressed as mean \pm SE. Data were analyzed using one-way ANOVA followed by t-test. $p$ value $<0.05$ was considered as significant [2].

\section{RESULTS}

\section{Percentage of extract determination}

The percentage of the TA bark methanol extract was $42.32 \mathrm{~g} \%$ shown in table 1.

Table 1: Percentage of extract from methanol of the bark of Terminalia arjuna

\begin{tabular}{lllll}
\hline Name of solvent & Amount (ml) & Amount of TA bark powder (g) & Amount of extract (g) & Percentage of extract (g\%) \\
\hline Methanol & 250 & 25 & 10.581 & 42.32 \\
\hline
\end{tabular}

\section{Column chromatograph analysis of methanol extract of TA bark}

In this study the crude methanol extract of TA bark was fractioned by column chromatographic technique using different solvents with specific ratio i.e. diethyl ether: acetone: methanol (5:3:2) and collected 35 fraction of methanol bark extract of TA. Then free radicals scavenging activity was determined of all collected fractions of TA bark using DPPH by colorimetric method. In this basis, the fractions 11 to 15 were re-fractioned by column chromatography and again analysis the free radicals scavenging activity.

As a result, we collected three fraction of TA bark on the basis of their antioxidant property such as F27, F28, F29 and they were showed good antioxidant property shown in fig. 1 .
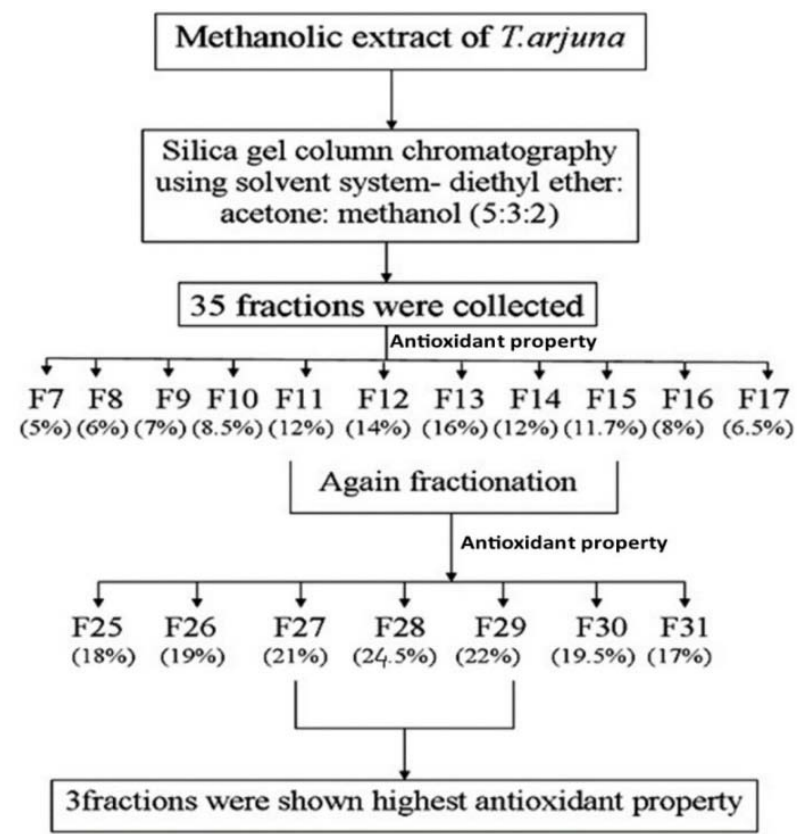

Fig. 1: The strategy for antioxidant activity guided fractionation of the total methanol extract from Terminalia arjuna (TA) bark

\section{Antioxidant activity determination by DPPH free radical scavenging assay}

DPPH is a stable free radical molecule and it gives strong absorption band at $517 \mathrm{~nm}$ in the visible arena of electromagnetic radiation. As antioxidant compounds donate protons to these radicals, the absorption decreases. When absorption decreases the optical density is taken as a determination of the wideness of radical scavenging activity. This result in the fig. 2 was compared with that of ascorbic acid and the methanol fractions of TA bark.

\section{Body weight}

The final Body weight was significantly elevated at the end of experiment in Groups I and IV animals compared to their initial body weight and other groups. In compare of Groups II, III and IV animals, the percentage of the body weight was increased for body growth which was drastically less than the other groups due to acetaminophen induced oxidative stress (table 2).

\section{Serum urea and creatinine}

In this study, there is a significant $(\mathrm{P}<0.05)$ increase in the plasma urea and creatinine concentrations in the Group II animals in comparison to the Group I, III, IV and V.

Moreover, oral co-administration of methanol fractions (F27, F28, F29) of TA bark for $15 \mathrm{~d}$ on Group III, IV, and V animals and significantly $(\mathrm{P}<0.05)$ decreased serum urea and creatinine level in group IV in comparison to the Group II, III and V. (table 3). 


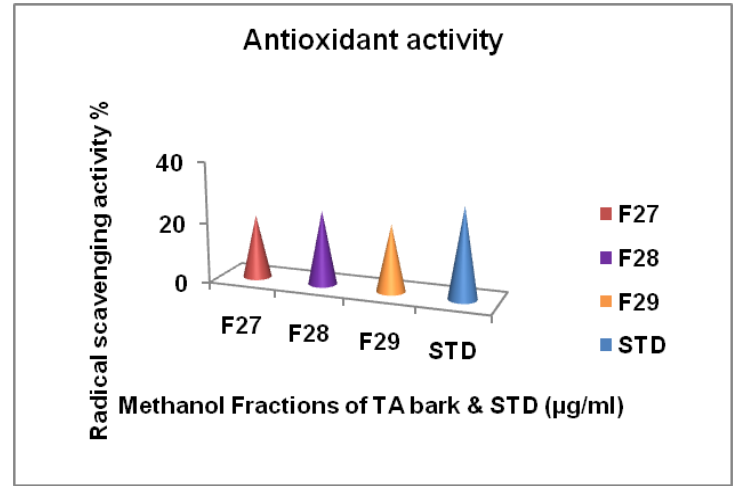

Fig. 2: DPPH free radical scavenging activity of methanol fractions (F27, F28, F29) of TA bark and standard STD-standard (Ascorbic acid)

\section{Activities of SOD and catalase}

Uremic animals (group II) were showed significant $(\mathrm{p}<0.05)$ decrease in plasma SOD and catalase level in comparison to group I animals. When rat was orally co-administration with the methanol fractions (F27, F28, F29) of TA bark for $15 \mathrm{~d}$ on Group III, IV, and V animals and significantly $(\mathrm{P}<0.05)$ increased plasma SOD and catalase level in group IV in comparison to the Group II, III and V. Also group I and IV animals were showed high SOD and catalase activity than other groups (table 4).

\section{Total phenolic content}

The total phenolic content of the F28 methanolic fraction was (815.48 \pm 8.11$) \mathrm{mg}$ gallic acid equivalent/g of extract.

\section{Detection of chemical compounds}

In fig. 3 the Proton NMR spectroscopy was used for the confirmation of structure of isolated compound; in which various peaks in $\mathrm{D}_{6} \mathrm{DMSO}$ were found at $\delta$ value in file 2 Peaks assigned: $-\mathrm{CH}_{3},-\mathrm{CH}_{2} \mathrm{OH}$ at 1.245 ppm., 2.518 ppm and file 1 Peaks assigned: $-\mathrm{CH}_{3},-\mathrm{CH}_{2} \mathrm{OH}$ at 1.242 ppm., 2.52 ppm., $5.244 \mathrm{ppm}$. olefinic protons of arjunoside IV, 6.568 ppm.,-OH arjunoside IV. ${ }^{1} \mathrm{H}$ NMR spectrum of F28 methanolic fraction displayed a proton broad singlet at $\delta 5.244$ which indicates the presence of olefinic proton. So, the present compound F28 methanol fraction was arjunoside IV which contained olefinic proton.

\section{DISCUSSION}

Nephrotoxicity is one of the most notable side effects and therapeutic limitations of analgesic and antipyretic drugs, especially acetaminophen. Oxidative stress related renal disease, induction of renal tubular necrosis, glomerular damage and renal inflammation are some of the major incident implicated in acetaminophen induced nephrotoxicity. In the present study, a novel establishment of the methanol fraction of TA bark was investigated for its further development as a natural medicinal agent for renal health [2].

Many epidemiological studies have been showed that the consumption of food consisting different plant parts like fruits, vegetables and other plant parts like bark, seed and leaf etc. was offered protection against some chronic diseases [16-19].

Plant was derived secondary metabolites such as alkaloids, polyphenols, saponins, and steroids are gaining much attention in recent years due to their imperative medicinal activities like antioxidant, anti-tumor, anti-diabetic, etc. [4]. This protection was suggested to be in part due to the intake of some advantageous nutrients including phytochemicals which were the most abundant antioxidants in our diets. TA is a widespread medicinal plant was used in the pharmacological system of medicine to care for various degenerative diseases [20].

Table 2: Effect of different fractions (F27, F28 and F29) of TA bark on body weight

\begin{tabular}{llll}
\hline Group & Initial body weight $\mathbf{( g )}$ & Final body weight $\mathbf{( g )}$ & Increases or decreases in body weight $(\mathbf{g} \%)$ \\
\hline I & $99.00 \pm 3.83$ & $122.00 \pm 5.16$ & $+23.23^{\mathrm{a}}$ \\
II & $98.33 \pm 4.30$ & $104.58 \pm 3.56$ & $+6.25^{\mathrm{b}}$ \\
III & $101.00 \pm 4.34$ & $113.34 \pm 3.56$ & $+12.34^{\mathrm{c}}$ \\
IV & $100.1 \pm 7.29$ & $124.00 \pm 5.60$ & $+23.90^{\mathrm{a}}$ \\
V & $109.00 \pm 3.25$ & $121.50 \pm 3.68$ & $+12.50^{\mathrm{c}}$ \\
\hline
\end{tabular}

Group I: control, Group II: Uremic, Group III: Uremic+F27 of M, Group IV: Uremic+F28 of M, Group V: Uremic+F29 of M. Data are expressed as mean \pm SE $(n=6)$. ANOVA followed by multiple two-tail t-test and data with different superscripts $(a, b, c)$ in a specific vertical column differ from each other significantly $(P<0.05)$. ' + ' indicates increase of body weight

Table 3: Effect of different fractions (F27, F28 and F29) of TA bark on plasma urea and creatinine level

\begin{tabular}{lll}
\hline Groups & Urea (mg/dl of plasma) & Creatinine (mg/dl of plasma) \\
\hline I & $20.16 \pm 0.93^{\mathrm{a}}$ & $1.05 \pm 0.22^{\mathrm{a}}$ \\
II & $50.3 \pm 3.12^{\mathrm{b}}$ & $4.80 \pm 1.94^{\mathrm{b}}$ \\
III & $44.58 \pm 1.8^{\mathrm{c}}$ & $3.29 \pm 1.44^{\mathrm{c}}$ \\
IV & $29.91 \pm 1.04^{\mathrm{d}}$ & $1.97 \pm 0.47^{\mathrm{d}}$ \\
V & $40.29 \pm 1.35^{\mathrm{c}}$ & $3.89 \pm 0.67^{\mathrm{c}}$ \\
\hline
\end{tabular}

Group I: control, Group II: Uremic, Group III: Uremic+F27 of M, Group IV: Uremic+F28 of M, Group V: Uremic+F29 of M. Data are expressed as mean \pm SE $(n=6)$. ANOVA followed by multiple two-tail t-test and data with different superscripts $(a, b, c, d)$ in a specific vertical column differ from each other significantly $(P<0.05)$

Table 4: Effect of different fractions (F27, F28 and F29) of TA bark on plasma SOD and catalase level

\begin{tabular}{lll}
\hline Groups & SOD (m mol of $\mathrm{H}_{2} \mathbf{O}_{2}$ consumption/dl of Plasma/min) & Catalase (m mol of $\mathrm{H}_{2} \mathbf{O}_{2}$ consumption/dl of Plasma/min) \\
\hline I & $0.70 \pm 0.09^{\mathrm{a}}$ & $0.92 \pm 0.05^{\mathrm{a}}$ \\
II & $0.29 \pm 0.12^{\mathrm{b}}$ & $0.35 \pm 0.12^{\mathrm{b}}$ \\
III & $0.33 \pm 0.08^{\mathrm{b}}$ & $0.40 \pm 0.08^{\mathrm{b}}$ \\
IV & $0.65 \pm 0.06^{\mathrm{a}}$ & $0.88 \pm 0.04^{\mathrm{a}}$ \\
V & $0.44 \pm 0.11^{\mathrm{c}}$ & $0.55 \pm 0.06^{\mathrm{c}}$ \\
\hline
\end{tabular}

Group I: control, Group II: Uremic, Group III: Uremic+F27 of M, Group IV: Uremic+F28 of M, Group V: Uremic+F29 of M. Data are expressed as mean $\pm \operatorname{SE}(n=6)$. ANOVA followed by multiple two-tail t-test and data with different superscripts $(a, b, c)$ in a specific vertical column differ from each other significantly $(P<0.05)$. 


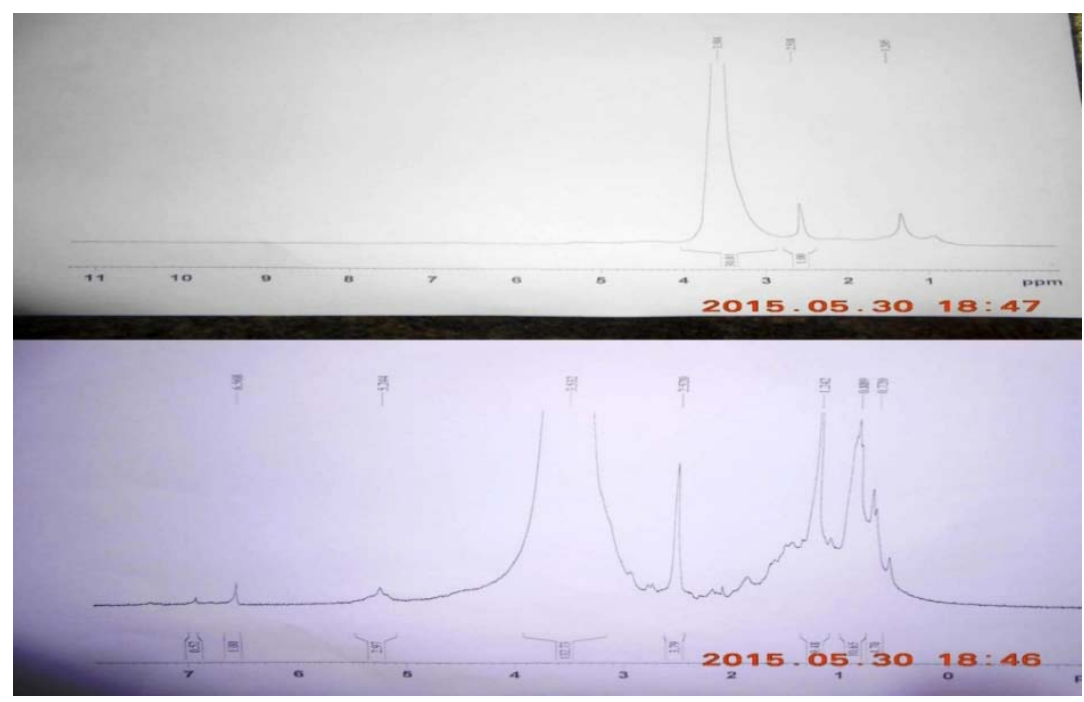

Fig. 3: 1H-NMR spectroscopy of isolated compounds from F28 methanol fraction of TA bark

The bark of TA is promising source of natural useful therapeutic agents and also it was contained different types of phytocompounds which have antioxidant activity, in my previous work [6]. F28 methanol fraction contained huge amount of polyphenols. So that, polyphenols are natural products which are recognized as one of the largest and most worldwide category of plant constituents occurring throughout the plant kingdom, and are also found in substantial levels in commonly consumed fruits, vegetables, beverages and other plant parts. Over dose of acetaminophen is often linked to many metabolic disorders including serum urea and creatinine derangements. Increased concentration of plasma urea and creatinine are considered for investigating drug induced nephrotoxicity in animals and human [21]. Blood urea nitrogen (BUN) was occurred in the hepatic protein which was originated from the diet or tissue source and was normally excreted in the urine. The serum urea was concentrated in kidney disorder because the rate of serum urea production surpasses the rate of clearance [22]. On the other hand, creatinine was commonly originated from internal source by the breakdown of tissue phosphor creatinine. Promotion of serum urea and creatinine levels was taken as the fundamental marker of nephrotoxicity [23-24]. Furthermore, oral co-administration of F27, F28, F29 methanol fraction of TA bark significantly $(\mathrm{p}<0.05)$ decreased plasma urea and creatinine level in Groups III, IV and V animals when compared to Group II animals and plasma urea and creatinine level were nearly same in group IV and I animals. Acetaminophen induced nephrotoxicity showed a significant $(p<0.05)$ increase in the plasma urea and creatinine levels in Group II (acetaminophen induced animals) rats when compared to Group I (control group). During kidney injury, free radicals like superoxide ions were generated at the site of damage tissue and modulated the SOD and Catalase activities, as a result in the depletion of antioxidant enzymes activity and accumulation of superoxide radical, causes damage the kidney. SOD and CAT are the most important antioxidant enzymes involved in ameliorating the effects of oxygen metabolism [25]. Previous studies have distinctly demonstrated that the acute APAP overdose defeats the antioxidant defense mechanisms in renal tissue. This is attributed to a free radical-mediated chain reaction which damages cell membranes [26]. The present study also demonstrated that acetaminophen overdose was resulted in a significant $(\mathrm{p}<0.05)$ decrease in the SOD and CAT activities in plasma of Group II animals, when compared with normal control rats (Group I animals). Uremic oxidative stress is characterized from a biochemical analysis, point of view as a state of reactive aldehyde and oxidized thiol group accumulation in the body, with depletion of reduced thiol group, which are particularly important as part of antioxidant defence mechanism [2] Acetaminophen induced oxidative stress in plasma has been established in this study to cause low activities of CAT and SOD, are important antioxidant enzymes. The decrease in the activity of antioxidant enzymes might be due to their use against the free radicals destruction and their inhibition by free radical species [27] The result of the present study was suggested that of the DPPH free radical scavenging assay indicate that the methanol fraction of TA bark exhibited strong scavenging activity on the DPPH free radical. The F28 methanol fraction of TA bark was showed highest antioxidant property in comparison to other fractions and standard (fig. 2). So that it was contained massive amount of phytocontitutes which have a powerful antioxidant property. According to bioactivity study, the F28 methanol fraction was showed outstanding antiuremic, nephro-protective and oxidative stress reducing property in comparison between other methanol fractions of TA bark. Recent studies were showed that the oxidative stress is heavily present in kidney disease patients [28]. So, F28 methanol fraction of TA barks was contained antioxidant compounds which were help to prevent uremia related oxidative stress in the body. NMR data was indicated that the F28 methanolic fraction of bark TA is contained arjunoside IV which is related to phenolic group compound which possesses highly antioxidant and anti-uremic properties. Finally, it can be concluded that TA bark has immense antioxidant potential which to be used in the areas of pharmacotherapy and as well as a prospective source of valuable drugs which were used for treating acetaminophen induced nephrotoxicity and oxidative stress.

\section{CONCLUSION}

In the present time herbal products are considered as a symbol of protection in contrast to the synthetic product that is regarded as risky to human life. Medicinal plants have therapeutic potential due to the occurrence of natural antioxidants such as vitamin C, vitamin E, carotenoids, flavonoids, polyphenols etc. So, based on the above results of the present study, it can be concluded that the methanol fraction (F28) of TA bark possess antioxidant and as well as antiuremic effects due to the presence of arjunoside IV which is related to phenolic group compound.

\section{ACKNOWLEDGEMENT}

We are thankful to the Honourable Principal Dr. Jayasree Laha, Raja N. L. Khan Women's College, Paschim Medinipur, West Bengal, India for providing us infrastructural facilities and also thankful to the UGC for financial support under Major Research Project [F. No. 41-68/2012(SR)] Authors are also grateful to Dr. Bidus Kanti Das, Indian Institute of Technology, Kharagpur for the improvement of the manuscript.

\section{AUTHORS CONTRIBUTION}

Shreya Mandal: She is the principal researcher in the field of phytotherapy and kidney disease. She carried out phytocompound isolation, safety assessment and animal experiments. She did as well as prepared the primary manuscript. 
Arpita Patra: She performed different biochemical estimations and also total antioxidant and phenolic compounds measurement.

Shrabani Pradhan: She participates in food formulation preparation and rat scarification during this investigation.

Suchismita Roy: She participates in food formulation preparation and rat scarification during this investigation.

Animesh Samanta: He assisted during artwork preparation and taking picture of NMR assay.

Koushik Das: He carried out the total grammatical check of manuscript.

Atiskumar Chattopadhyay: He is the expert in the field of human physiology and molecular biology. He participates in the manuscript check.

Dilip Kumar Nandi: For more than $25 \mathrm{y}$, he is devoted with kidney disease and nutritional aspects basically phyto-medicine and functional food application.

\section{CONFLICT OF INTERESTS}

We declare that we have no conflict of interest.

\section{REFERENCES}

1. Jawala S, Gupta AK, Singla R, Gupta V. General awareness and relative popularity of Allopathic, Ayurvedic and homeopathic system. J Chem Pharm Res 2009;1:105-12.

2. Pradhan S, Mandal S, Roy S, Mandal A, Das K, Nandi DK. Attenuation of uremia by orally feeding alpha-lipoic acid on acetaminophen induced uremic rats. Saudi Pharm J 2013;21:187-92.

3. Mandal A, Nandi DK, Roy S, Das K, Mondal KC. In vivo assessment of bacterio therapy on acetaminophen induced uremic rats. J Nephrol 2013;26:228-36.

4. Sreenath KB, Sundaram S, Gopalakrishnan VK, Poornima K. Quantitative phytochemical analysis, in vitro antioxidant potential and gas chromatography-mass spectrometry studies in ethanolic extract of Azolla microphylla. Asian J Pharm Clin Res 2016;9:318-23.

5. Vasu K, Goud JV, Suryam A, Singara Chary MA. Biomolecular and phytochemical analyses of three aquatic angiosperms. Afr J Microbiol Res 2009;3:418-21.

6. Kinsalin VA, Kumar PS, Duraipandiyan V, Ignacimuthu S, AlDhabi NA. Antimicrobial activity of methanol extracts of some traditional medicinal plants from Tamil Nadu, India. Asian J Pharm Clin Res 2014;7 Suppl 1:36-40.

7. Patra JK, Gouda S, Sahoo SK, Thatoi HN. Chromatography separation. ${ }^{1} \mathrm{H}$ NMR analysis and bioautography screening of methanol extract of Excoecaria agallocha L. from Bhitarkanika, Orissa, India. Asian Pac J Trop Biomed 2012;2:50-6.

8. Barros L, Falcao S, Baptista P, Freire C, Vilas-Boas M, Ferreira IC. Antioxidant activity of Agaricus sp. mushrooms by chemical, biochemical and electrochemical assays. Food Chem 2008; 111:61-6.

9. Olfert ED, Cross BM, McWilliam AA. Guide to the care and use of experimental animals. 2nd ed. Canada: Ottawa; 1993.
10. Burtis CA, Ashwood ER. Tietz Textbook of Clinical Chemistry. $3^{\text {rd }}$ ed. Philadelphia: 1999.

11. Singh RK, Gautam RK, Karchuli MS. Evaluation of nephroprotective activity of Mentha arvensis in cisplatininduced nephrotoxicity. Asian J Pharm Clin Res 2014;7:188-91.

12. Praharsheta Am, Samuel V, Nirmala P. Role of ebselen, a selenoorgano compound in cisplatin induced nephrotoxicity in wistar rats. Int J Curr Pharm Res 2015;7:57-9.

13. Marklund S, Marklund G. Involvement of superoxide anion radical in auto-oxidation of pyrogallol and a convenient assay of superoxide dismutase. Eur J Biochem 1974;47:469-74.

14. Demiray S, Pintado ME, Castro PML. Evaluation of phenolic profiles and antioxidant activities of turkish medicinal plants: Tilia argentea, Crataegi folium leaves and Polygonum bistorta roots. World Acad Sci Eng Technol 2009;54:312-17.

15. Haque AM, Hassan MM, Das A, Begum B, Ali MY, Morshed H. Phytochemical investigation of Vernonia cinerea. J Appl Pharm Sci 2012;2:79-83.

16. Arts CW, Hollman PCH. Polyphenols and disease risk in epidemiologic studies. Am J Clin Nutr 2005;81:317-25.

17. Chang-Claude J, Frentzel-Beyne R, Eilber U. Mortality pattern of German vegetarians after $11 \mathrm{y}$ of follow up. Epidemiology 1992;3:395-401.

18. Graf BA, Milbury PE, Blumberg JB. Flavonols, flavonones, flavanones and human health: Epidemiological evidence. J Med Food 2005;8:281-90.

19. Phillips R, Lemon F, Beeson L, Kuzma J. Coronary heart disease mortality among Seventh-Day Adventists with differing dietary habits: a preliminary report. Am J Clin Nutr 1978;31:191-8.

20. Nema R, Jain P, Khare S, Pradhan A, Gupta A, Singh D. Antibacterial and antifungal activity of Terminalia arjuna leaves extract with special reference to flavonoids. Basic Res J Med Clin Sci 2012;1:63-5.

21. Ohkawa H, Ohishi N, Yagi K. Assay for lipid peroxidation in animal tissues by thiobarbituric acid reaction. Anal Biochem 1979; $95: 351-8$

22. Mayne PD. The kidneys and renal calculi. In: Clinical chemistry in diagnosis and treatment (Eds.). London: Edward Arnold Publications; 1994.

23. Anwar S, Khan NA, Amin KMY, Ahmad G. Effects of Banadiq-al Buzoor in Some Renal Disorders. Pakistan: Karachi; 1999.

24. Bennit WM, Parker RA, Elliot WC, Gilbert DN, Houghton DC. Sex related differences in the susceptibility of rat to gentamicin nephrotoxicity. J Infect Dis 1982;145:370-3.

25. EI-Sokkary GH, Kamel ES, Reiter RJ. Prophylactic effect melatonin in reducing lead-induced neurotoxicity in the rat Cell Mol Biol Lett 2003;8:461-70.

26. Pradhan S, Roy S, Mandal S, Das K, Das S, Nandi DK. Protective effect of alpha-lipoic acid on hepato renal toxicity on acetaminophen induced uremic male albino rat. Eur J Biomed Pharm Sci 2016;3:668-74.

27. Debnath D, Mandal TK. Study of quinalphos (an environmental oestrogenic insecticide) formulation (Ekalux 25 E. C.)-induced damage of the testicular tissues and antioxidant defense systems in sprague-dawley albino rats. J Appl Toxicol 2000;20:197-204.

28. Vaziri ND. Oxidative stress in uremia: nature, mechanisms and potential consequences. Semin Nephrol 2004;24:469-73. 